\title{
Comparison of Calculated and Measured Helicopter Rotor Lateral Flapping Angles
}

\section{Wayne Johnson}

(HASA-TE-81213) COMPARISON OE CALCULATED AND MEASURFD HELICOPTER ROTOR LATEKAL

FLAP PING ANGLES (NASA) $27 \mathrm{~g}$ aC AU3/M $\overrightarrow{\mathrm{r}}$ AU1 CSCL $01 \mathrm{~A}$ $\sqrt{30}-33349$

Unclas

$240<9$

July 1980

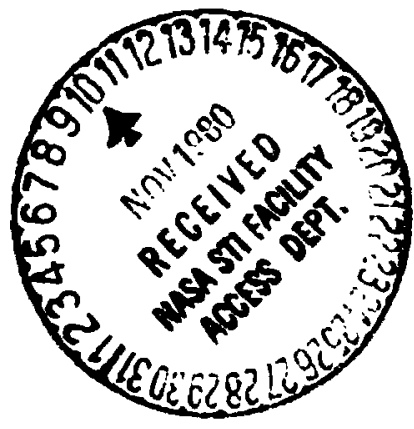




\section{Comparison of Calculated and Measured Helicopter Rotor Lateral Flapping Angles}

\section{Wayne Johnson, Aeromechanics Laboratory AVRADCOM Research and Technology Laboratories Ames Research Center, Moffett Field, Californịa}


COMPARISON OF GALCULATED AND MEASURED

HELICOPTSR ROTOR LATERAL FLAPPING AMGLS

\author{
Mayne Johnson* \\ U.S. Army Reseerch and Technoloes Laboratories (AVRADCoM) \\ MASA. Ames Research Center \\ Moffett Field, California
}

ABSTRACT

Calculated and measured val les of hellcopter rotor flapplag argles In forward flight are compared for a model rotor in a wind tunnel and an autogico in gliding flight. The lateral flappling angles can be accurately predicted when a calculation of the nonuniform wake-induced velocity is used. At low advance ratios, it is also necessary to use a free wake geometry calculation. For the cases considered, tine tip vortices in the rotor wake remain very close to the tip-path plane, so the calculated values of the flapping notion are sensitive to the fine detalls of the rake structure, specifically the viscous core radius of the tip vortices.

*Head of Rotorcraft Research Section, Large Scale Aerodynamics Branch 


\section{IMTRODUCTION}

The blades of an articulated hellcopter rotor have a hinge at the blade root that allows out-of-plane motion called flapping. In forward flight a once-per-revolution notion of the blade about the flap hinge is produced, that corresponds to longltudimal and lateral tilt of the rotor tip-path plane relative to the shaft. Such motion occurs with hingeless and bearingless helloopter rotor designs as well, due to blade bending at the root rather than rotation about a flap hinge. The sinplest analyses of hellcopter rotor behavior assume that the induced velocity distribution is constant over the rotor disk. In fact however, the induced velocity distribution is highly nonuniform, and the rotor blade lapping motion is quite sensitive to the Inflow distribution. Consider a longitudinal gradlent of the Induced veloctty, Increasing from the leading edge to the tralling edge of the rotor disk. The blade lift produced is such a distribution will be reater on the front of the disk than on the rear. so the rotor will be subjected to a longltudinal aerodynanic moment. An articulated rotoi responds to this monent like a grro, so the tip-path plane tilts laterally, towand the advancing side. Sinilarly a lateral Inflow variation will produce a roll monent on the rotor, and hence a longitudinal tip-path plane tilt. With a hingeless rotor, the magritude of the flapping response to nonuniform Inflow is not greatly affected, but the phase of the response can be significantly decreased, so that a longitudinal inflow variation can produce longltudinal flapping as well as lateral flapping. Because of this sensitivity to the Induced velocity distribution, it is difficult to calculate rotor blade flapping in forward 
flight. An accurate calculation of flappling is needed in onder to predict longitudimal and lateral cy ilic control positions, particularly for new hellcopter designs. Moreover, since the blade flap notion represents the integrated effect of the $1 /$ rev aerodynamic enviroment of the rotor. difficulties in calculating it have serlous inplications regarding the predictive capabilit: of rotor aorodynanic analyses in general.

In 1934. Wheatley ${ }^{1}$ extended the theory of Glauert and Lock for the calculation of belicopter rotor forces and blade motion in forward flight. He evaluated the accuracy of the theory by comparing with flight test results for a Pitcairn autogiro in a glide. The rotor anglo-of-attack. rotational speed, thrust coefficlent, and longltudinal flapping angle were predicted with good accuracy, up to an advance ratlo of about 0.4 or 0.5 . The prediction of the lateral flapping angle was consistently low however. Wheatley identified the use of uniform inflow as the most critical assumption of the analysis. The sensitivity of the lateral flapping calculation to nonuniform Inflow was demonstrated by using an induced velocity distribution that varied Innearly from the leading edge to the trailing edge of the rotor disk. With such a longitudinal inflow varlation, the prediction of the lateral flapping was inproved, but was still significantly low (for an amplitude of the variation equal to $50 \%$ of the mean value). Wheatley concluded that the rotor blade flap motion can not be rigorously calculated without an accurats determination of the wake-Induced inflow velocities.

In 1972. Harris ${ }^{2}$ conducted a wind tunnel test of a model hellcopter rotcr, to examine the influence of advance ratlo, thrust, and shaft 
angle-of-attack on the rotor flapping angles. He found a large discrepancy between the measured lateral flapping and the values calculated using uniform Inflow. Longltudinal flapping was estimated falrly well using uniform Inflow, as were the trends with thrust and shaft angle. By using a nonuniform induced velocity calculation based on undistorted wake geometry. the prediction of lateral flapping was improved, but the measured results were still significantly underestimated at low advance ratio. Harris suggested that the prinary source of the remalning discrepancy was the use of undistorted wake geometry.

The conclusions of Wheatley and Harris have remained conjectural. It is the purpose of this paper to examine the influence of nonuniform Inflow and wake geonetry on the calculation of hellcopter rotor lateral flapping angles. The intent also is to establish the adequacy of the wake model in a hellcopter rotor analysis, to the exter that may be inferred by comparisons with measurements of blade flapping motion.

\section{ANALYTICAL MOSI}

The rotor flapping motion was calculated using the helicopter analysis describei in reference 3. The wake amalysis was based on a discrete element representation of the vorticity, with models for the wake rollup and distorted wake geometry. The free wake geometry was calculated using the analysis of reference 4. The blade aerodynamic loading was calculated using lifting lins theory, with corrections for three-dinensional effects at the tig and at blade-vortex interactions. The rotor blade flap motion was calculated by means of a harmonic analysis method. Rigld body flap 
motion was the only degree of freedom considered. Four harmonics of the blade motion were calculated, using an azinuthal increment of $15^{\circ}$. Including blade lag motion, bending motion, or up to 10 hamonics in the calculation had ilttle effect on the tip-path plane tilt. The effects of the blade torsion motion are discussed later in the paper. The flap motion relative to the shaft may be written as a Fourler series:

$$
\beta=\beta_{0}+\beta_{1 c} \cos \psi+\beta_{1 s} \sin \psi+\text { higher harmonics }
$$

Here $\beta_{1 c}$ is the longitudinal tilt angle of the tip-path flane relative to the shaft. positive for forvard tilt; $i_{1 s}$ is the lateral angle, positive for tilt toward the retreating side of the disk; and $\psi$ is the blade azimuth angle, measured from townstreem. If there is no cyclic pitch, both $\beta_{1 c}$ and $\beta_{1 s}$ w1ll be negative in forward flight.

The Induced velocity, circulation, and lift were evaluated at 15 stations along the blade, concentrated toward the tip. The trailed -vorticity in the wake directly behind the blade was represented by discrete vortex lines positioned midway between the polnts at which the circulation was calculated. The strength of each trailed line was defined by the difference between the bound circulation at successive radial stations. This part of the model is a comnon numerical implementation of lifting Ine theory. For the rotary wing it is necessary also to model the rollup of the vortlcity Into a concentrated tip vortex, because the blade encounters the wake from the precering blaries as 1t rotates. Therefore, after an azimuthal extent of $30^{\circ}$ in this case, the tralled vorticity was concentrated Into a single tip vortex line, with strength equal to the maximum bound clrculation of the blade. For conservation of vorticity, 
there must be an Inboard sheet of trailed vorticity with equal total strength and opposite sign as the tip vortex. This inboard sheet is much less important that the tip vortex, partly because the vorticity is not as concentrated and partly because it tends to be convected downrard faster than the tip vortex. Consequently the entire inboard sheet could be reasombly represented by a single vortex line, w1th a large core radius (about 45\% of the rotor radius in this case) to avoid unrealistically large induced velocities when the wake passed under the following blade. The bound clrculation in forward flight varles azimuthally as well as radially, so the shed wake must also be included. The shed wake was modelled by radial, discrete vortex lines (also with a large core radius). A sinilar wake model was used for the other blades of the rotor. The detalled near wake model need not be used for these other blades since it is far from where the induced velocity is being calculated on the first blade. The curved trailed vortex elements in the wake are represented by a connected serfes of straight line segments, with an amimuthal increment of $15^{\circ}$ in this case. The vorticity strength varied inearly along each vortex Iine elenent, both tralled and shed. Four revolutions of the wake behind each blade were modelled in this fashion. It was determined that three revolutions were sufficlent, except at the very lowest advance ratio analyzed.

A distributed vorticity model was used for the tip vortex core, In which one-half the vorticity was outside the core radius (defined at the puint of maximum tangential velocity). With this model, the maximum velocicy induced by the vortex was half that of a vortex with all the vorticity concentrated inside the core radius. 
An und is torted wake geometry is obtained by assuming that each element of vorticity in the wake is convected dowmard at a rate equal to the mean induced velocity over the rotor disk, as the blades rotate and the hellcopter flies forward. The resulting geometry consists of skewed, Interlocking hellces, one hehind each blade. The self-induced distortion of the wake is neglected in this model. The analysis of reference 4 was used to calculate the distorted, free wake geometry in forward flioht. The free wake geometry was calculated for the tip vortices only, for two revolutions of the wake behind each blade. Only two iterations within the free wake geometry calculation were necessary.

The analysis progressed in three stages. In the first stage, the blade motion and loading were calculated using uniform inflow. Next the wake influence coefficients were calculated with an undistorted wake geometry, and the motion and loading obtained using nonuniform inflow. Finally, the free wake geometry was calculated, the influence coefficlents were re-evaluated, and the blade motion and loading again obtained using nonuniform Inflow. It was determined that oultting any of these three stages gave unconverged results, but it was not necessary to repeat any stage before going on to the next. Within each stage, there was an iteration so that the calculated induced velocity and bound circulation were consistent. Aiso within each stage, there was an iteration on the collective pitch, in order to trim the rotor thrust to a prescribed value.

\section{COMPARISON WITH WIND TUNNEL DATA}

Harris measured the flapping angles of a model rotor in a wind tunnel. The principal parameters defining the rotor and operating conditions are $-7-$ 
Table 1. Rotcr Parameters and Operating Conditions

\begin{tabular}{lll} 
& Model Rctor & Autogiro Rotor \\
\cline { 2 - 3 } Radius, $R$ & $0.832 \mathrm{~m}$ & $6.86 \mathrm{~m}$ \\
Number of blades & 4 & 4 \\
Solidity, $\sigma$ & 0.0891 & 0.1037 \\
Lock number & 5.80 & 19.1 \\
Flap hinge offset, e/R & 0.0229 & 0.0125 \\
Twist & $-9.14^{\circ}$ & $50^{\circ}$ \\
Longitudinal cyclic & $0.73^{\circ}$ & $0^{\circ}$ \\
Lateral cyclic & $0^{0}$ & $0^{\circ}$ \\
Tip speed, $\Omega \mathrm{R}$ & $137 . \mathrm{m} / \mathrm{sec}$ & $102 . \mathrm{m} / \mathrm{sec}$ \\
Nominal $\mathrm{C} / \sigma$ & 0.080 & 0.064 \\
Airfoil & V23010-1.58 & Gottingen 429 \\
Source of data & Reference 2 & Reference 1
\end{tabular}


given in table 1. Complete detalls of the rotor and test data may be found in reference 2. An accuracy of $\neq 0.25^{\circ}$ is given for the flapping measurements. The wind tunnel had partly slotted walls, designed to produce no angle-ofattack change due to wall constralnts, and the rotor diameter wi. $\therefore$. ily $27 \%$ of the tunnel width. Flow breakdown was estimated to occur at advance ratios below 0.04 .

Floure 1 compares the calculated and measured values of the lateral flappling angle as a function of advance ratio, for a thrust coefficient to solidity ratio of 0.08 and a tip-path plane angle-of-attack of approximately $1^{\circ}$ (aft tilt). For reference, a helicopter at an advance ratio of 0.15 would typically have a tip-path plane angle-of-attack of approximately $1^{\circ}$ forward. The lateral flappling is underpredicted when uniform inflow is used, and even when nonuniform inflow based on the undistorted wake geometry is used. Below an advance ratio of about 0.16 , it is necessary to Include the free wake calculation in order to obtain a good estinate of the lateral flapping. Figure 2 shows the corresponding resuits for the longltudinal flapping angle, for which there is much less influence of the inflow model. The free wake geometry analysis was not applicable at hover and very low speed, so no calculated results are shown for advance rat sos below 0.04 . It was also found that the induced porer calculation was significantly Influenced by the wake model. Below an advance ratio of about 0.10 , the calculated Induced power was actually less than the 1deal momentum theory value when the undistorted wake geometry was used, but was appropriately greater than the ideal value w1th the free wake geometry. For advance 
ratios greater than 0.15 , the calculated Induced power was about the same for the two models.

Figure 3 shows the calculated vertical displacement of the tip vortices relative to the tip-path plane, for the two wake geometry models. The wake geometry is shown as a function of the wake age $\phi$ (the azimuth angle along the wake helix), for the rotor blade at four azimuth angles. The significant self-induced distortion of the free wake ge. metry is evident, resulting in numerous blade-vortex interactions in which the vertical separation is a fraction of the blade chord (which is $7 \%$ of the rotor radius). The tip vortices even pass above the blades initialiy, a behavior that has been observed experimentally as well. ${ }^{5}$ Figure 4 shows the influence of the wake geometry on the calculated induced velocity. The discrete tip rortices of the rotor wake produce a $1 /$ rev variation of the inducer? veizcity that corresponds to a longitudinal gradient over the rotor disk, and hence increases the lateral flapping. By moving the wake closer te the tip-path plane, the lnduced velocity chang's on the sldes of the ti $x_{2}$ where the blades sweep over the tip vortices, is greatly lncreased. Consequently the wake geonetry is an important facto. In determining the lateral flapping at low advance ratto and low tip-path plane tilt.

In the cases considered here, the free wake geometry places the tip vortices so close to the blades that the calculated flapping is sensitive to the value of the viscous core radius, which determines the maximun velocity induced by the vortex. For the calculations fresented in figures 1 to 4 , a core radius of $0.05 \mathrm{R}$ was used. No measurements of the core radius are avallable for the nodel rotor being analyzed, so this value 
was chosen based on the correlation produced. FIgure 5 shows the sensitivity of the calculated Induced velocity to the tip vortex core radius, and table 2 shows the corresponding calculated flapping angles. With the undistorted wake geometry, there is little influence of the core radius. These values of the vortex core radius should not be interpreted too literally however. There are a s'mber of factors in addition to the core radius that combine to determine the magnitude of the vortex-induced loading, including the tip vortex stength, the extent of tine tip vortex rollup, lifting surface effects on the induced blade loading, and possibly even vortex bursting or vortex-induced stall on the blade. In the absense of complete information about each of these phenomena, the vortex core radius is a convenient paraneter with which to account for their cumulative Influence on the rotor blace loading.

Flgure 6 compares the measured and calculated values of the lateral flapping as a function of thrust, at an advance ratio of 0.08 and shaft angle of $-1.35^{\circ}$. The free wake geometcy is required to accurately predict the rate of change of $\beta_{1 s}$ w1th $C_{T} / \sigma$, and $1 t$ is increasingly 1mportant at high thrust. Figure? compares the measured and calculated values of the lateral flapping as a function of the shaft angle-of-attack, at an advarce ratio of 0.08 and a collective pitch of $11^{\circ}$.

In all cases, the collective pitch was adjusted to trim the calculated thrust to the measured value. It was found that the calculated collective pitch angles were consistently lower than the measured values, a connon result in rotor analyses that may usually be attributed to elastic pitch 
Table 2. Calculated influence of vortex core radius on blade

$$
\begin{aligned}
& \text { flapping angles }\left(\mu=0.1, C_{T} / \sigma=0.08\right. \text {, and } \\
& \left.\alpha_{t p p} \cong 1^{\circ}\right)
\end{aligned}
$$

\begin{tabular}{|c|c|c|}
\hline & $\begin{array}{c}\text { Flapping } \\
\beta_{1 c}\end{array}$ & $\begin{array}{l}\left.\beta_{18}^{(d e g}\right) \\
\beta_{18}\end{array}$ \\
\hline \multicolumn{3}{|l|}{ Free wake geometry } \\
\hline core radius, $r_{c}=0.010 R$ & -2.08 & -4.17 \\
\hline $0.030 \mathrm{R}$ & -2.47 & -3.39 \\
\hline $0.050 R$ & -2.57 & -3.13 \\
\hline $0.075 R$ & -2.56 & -2.67 \\
\hline $0.100 R$ & -2.52 & -2.68 \\
\hline \multicolumn{3}{|l|}{ Undistorted wake geometry } \\
\hline core radius, $r_{c}=0.010 R$ & -2.77 & -1.69 \\
\hline 0.0308 & -2.73 & -1.70 \\
\hline $0.050 \mathrm{R}$ & -2.70 & -1.70 \\
\hline $0.075 R$ & -2.66 & -1.68 \\
\hline $0.100 R$ & -2.62 & -1.65 \\
\hline
\end{tabular}


deflection of the blade. Insufflclent information was avallable regarding the physical characteristics deternining the blade torsion dynamics (control system and blade stlffness, blade lnerila and center-of-gravity distributlons. and the aerodynanic conter distribution) to allow an exploration of this facet of the analyols.

\section{COMPARISON WITH FLIGHT DATA}

Wheatley measured the flapping angles of an autogiro in gliding flight. The rotor and operating paraneters are sunarized in table 1; complete details of the alrcraft and test data are given in references 1 and 6. An accuracy of $\neq 0.1^{\circ}$ is given for the flapplng measurenents. In the calculations the rotor was tringed by setting the shaft angle-ofattack to the measured value, and adjusting the collective pitch to obtain the measured value of the rotor thrust coefficient. On an autogiro the rotor has a positive angle-of-attack (aft tilt of the tip-path plane), that becomes fairly large at low advance ratio.

Figure 8 compares the calculated and measured values of the lateral flapping as a function of advance atio. Again it is essential to use sonuntform inflow in order to accurately prodict the flapping angles. and below an advance ratio of about 0.20 it is also necessary to use the free wake geometry. Flgure 9 shows the corresponding results for the longltudinal flappling. for which the influence of the nonuniform Inflow is smaller but not negligible. 


\section{CONCUUDEIG RENARKS}

Calculated and measured values of hellcopter rotor flappling angles In forward flight have been compared for a model rotor In a wind tunnel and an autogiro rotor in gliding fight. It has been confined that the discrepancy between the experimental data and theories based on uniform Inflow is attributable primarily to the highly nomulform velocity induced at the blades by the tip vortices in the rotor wake. By using an analysis based on a calculation of the nomuniform innow. It was possible to accurately calculate the rotor lateral flapping angles. At low advance ratios it is also necessary to use a free wake geonetry, a result anticipated by harris although not by theatley. The degree of sensitivity of an integrated effect of the rotor aerodynamic enviroment (the lateral flapplng angle) to the fine structure of the wake is perhaps surprising, but plausible upon examination of the phenomenon. It is concluded that the principal features of the rotor wake are correctly represented in the nonunifom inflow and free wake geometry models utilized in this investigation. To correlate and develop these models further w1ll require experimental data that encompasses the rine detalls of the rotor aerodynamics, such as measurements of the tip vortex circulation, core size, and peak velocities, even when the parameters of most interest are the integrated effects such as the first harmonic flapping motion. 


\section{Propriticas}

1. Wheatley. Joha B.. -An Aerodymanic Amaljsis of the Autortro Rotor with a Conparison between Calculated and Bxparinental Results." MCA Report 10. 487.1934

2. Harris, Mranilin D.. Artlculated Rotor Blade Flapplos Motion at Iow Advance Rat10," Journal of the Anerican Hellcopter Soclety. Vo1. 17. 10. 1. Jamnery 1972

3. Johnson, Jayne, "A Conprehensive Amiftical Hodel of Rotoreraft Aerodymancs and Dymance." IASA In 81182, 1980

4. Seully. M.P.. "Conputation of Rellcopter Rotor Vake Geosetry and Its Influence on Rotor Harmonic Alrloads." Messachusetts Institute of Technology. ASTL UR 178-1. March 197.

5. Sinors, I.A.. Pacifico, R.S., and Jones, J.P.. "The Hovenent, Structure, and Breakdown of Trailing Vortices fron a Botc- Blade." CAL/AVLabs Sympos 1un, Buffalo, Now Iork, June 196

6. Wheatlej. John B.. WIng Pressure D1stribution anu Rotor-Blade Motion of an Autogiro as Deternined in F11ght." MaA Report No. 475. 1934 
O EXPERIMENT

- - UNIFORM INFLOW

- NONUNIFORM INFLOW, UNDISTORTED WAKE

- NONUNIFORM INFLOW, FREE WAKE

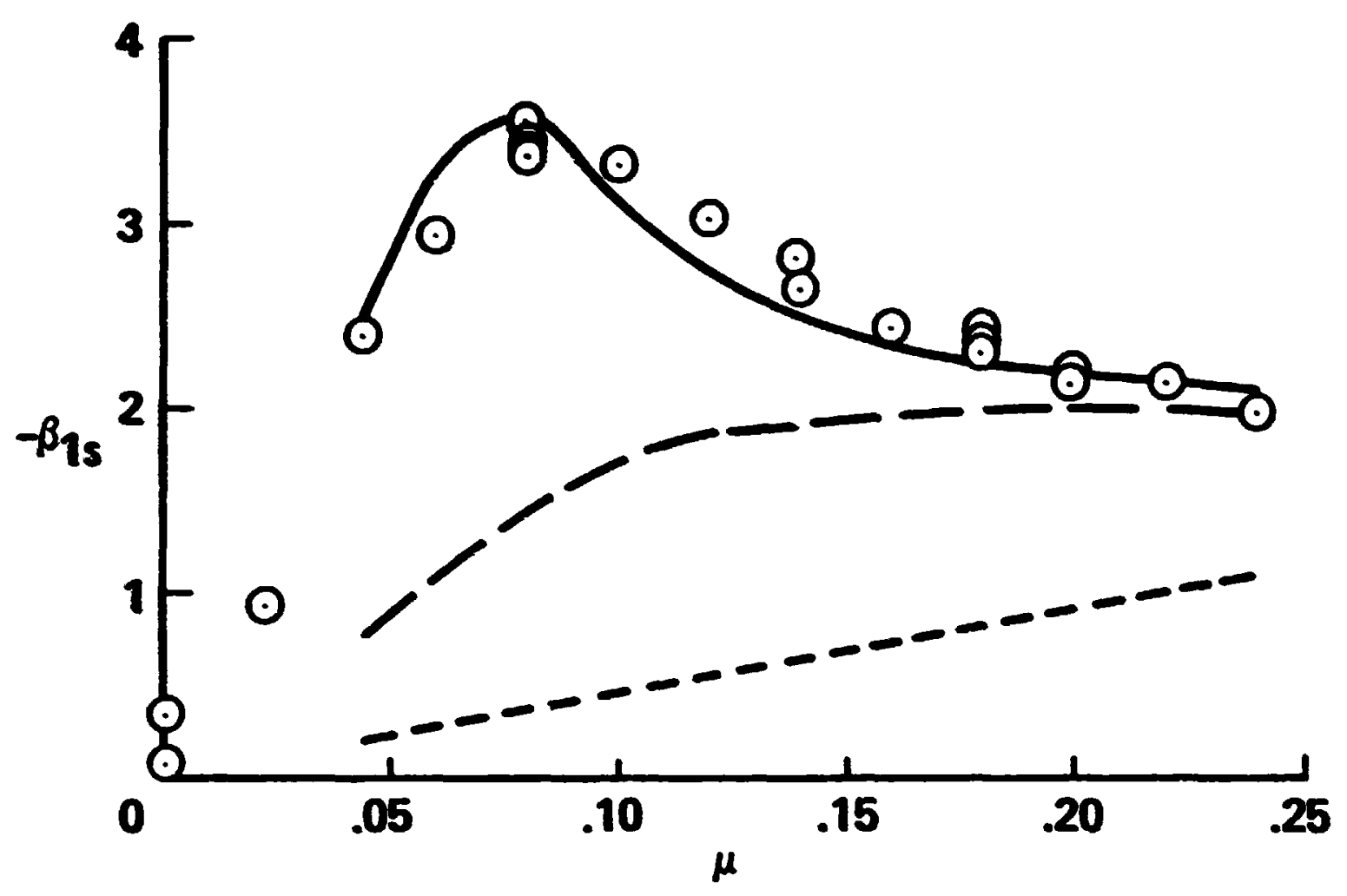

Flgure 1. Comparison of measured and calculated model rotor laceral flapping angles as a function of advance ratio $\left(C_{T} / \leftarrow=0.09\right.$ and $\left.\alpha_{\text {tpp }} ¥_{1}{ }^{\circ}\right)$ 


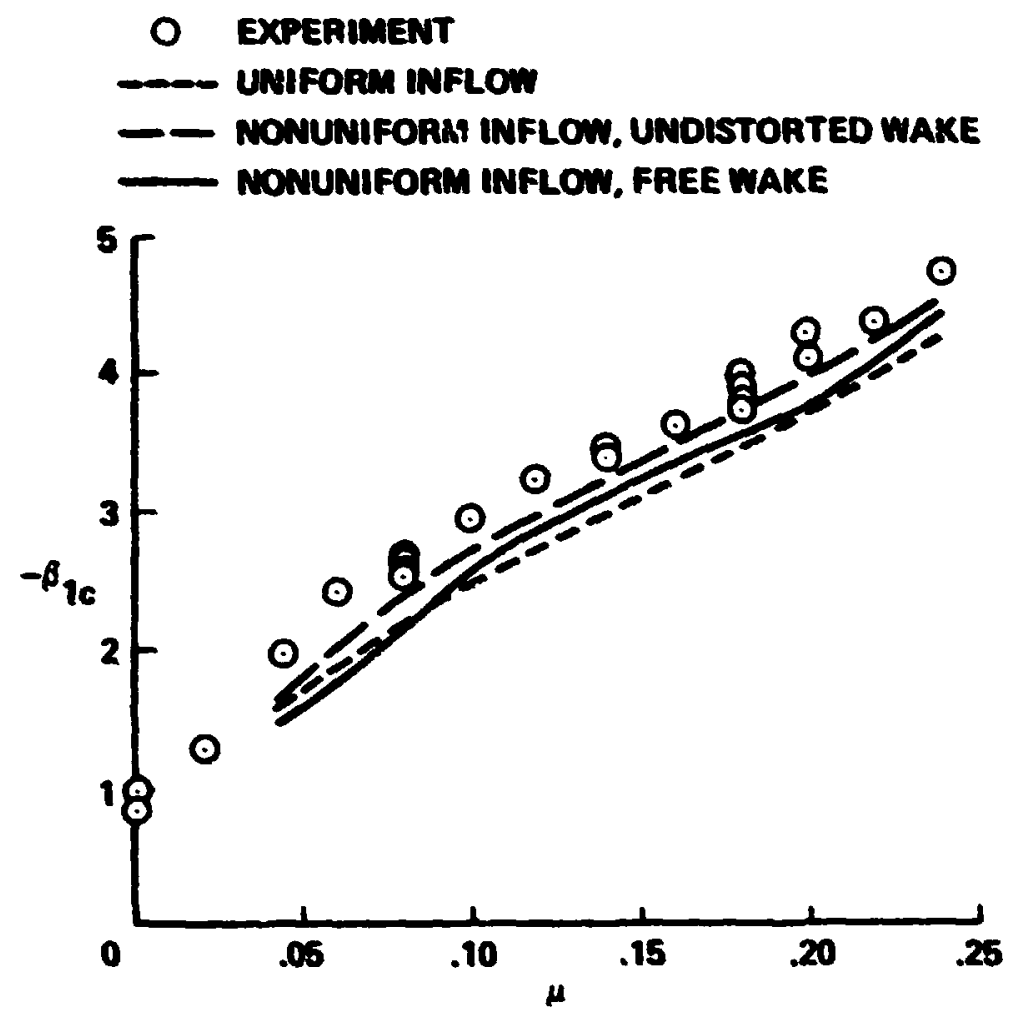

Figure 2. Comparison of measured and calculated model rotor longitudinal flapping angles as a function of advance rat10 $\left(C_{\mathrm{g}} / \sigma=0.08\right.$ and $\left.\alpha_{\mathrm{tpp}} \cong 1^{\circ}\right)$ 

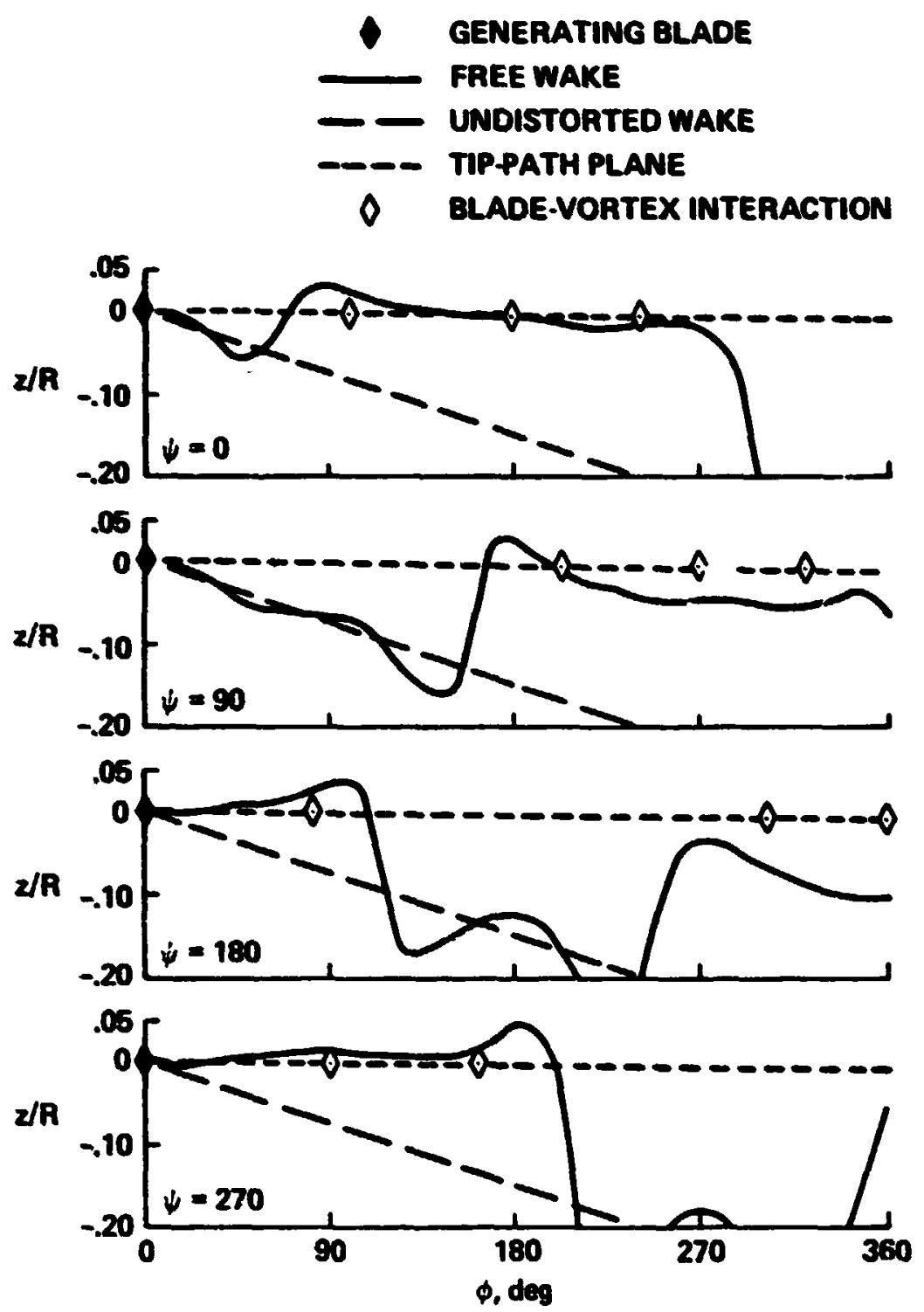

F1gure 3. Calculated tip vortex vertical displacement

$$
\left(\mu=0.1, c_{p} / \sigma=0.08 \text {, and } \alpha_{\text {tpp }} \cong 1^{\circ}\right)
$$




\section{- - UNIFORM INFLOW}

- NONUNIFORM INFLOW. UNDISTORTEO WAKE NONUNIFORM INFLOW, FREE WAKE

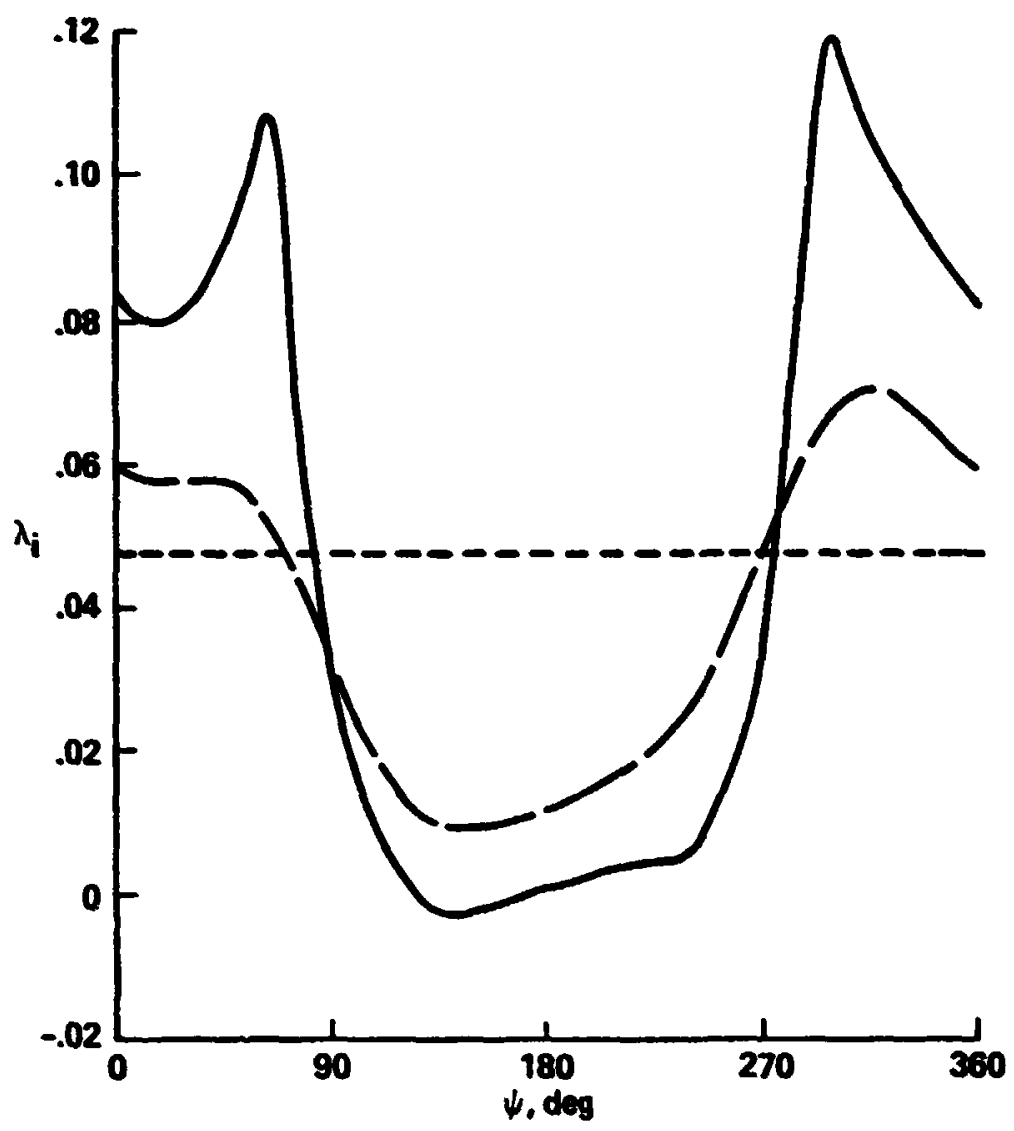

Figure 4. Calculated induced velocity at radias station $r / R=0.92$ for the three wake models $(\mu=0.1$. $c_{T} / \sigma=0.08$, and $\left.\alpha_{t p p} \cong 1^{\circ}\right)$ 


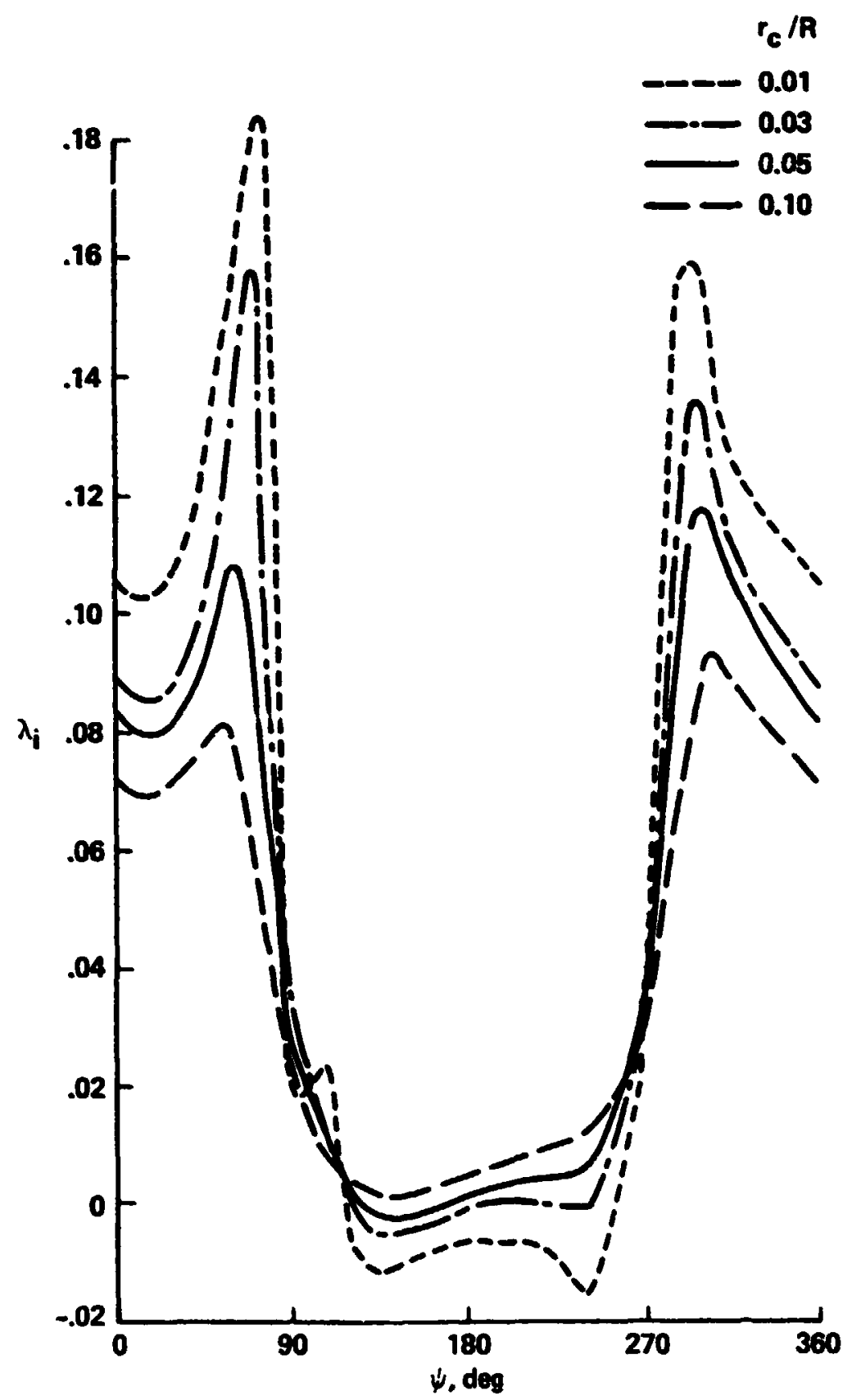

Figure 5. Calculated induced velocity at radial station

$r / R=0.92$ using the free wake model, as a function of tip vortex core radius $\left(\mu=0.1, c_{T} / \sigma=0.08\right.$, and $\alpha_{\text {tpp }} \cong 1^{\circ}$ ) 


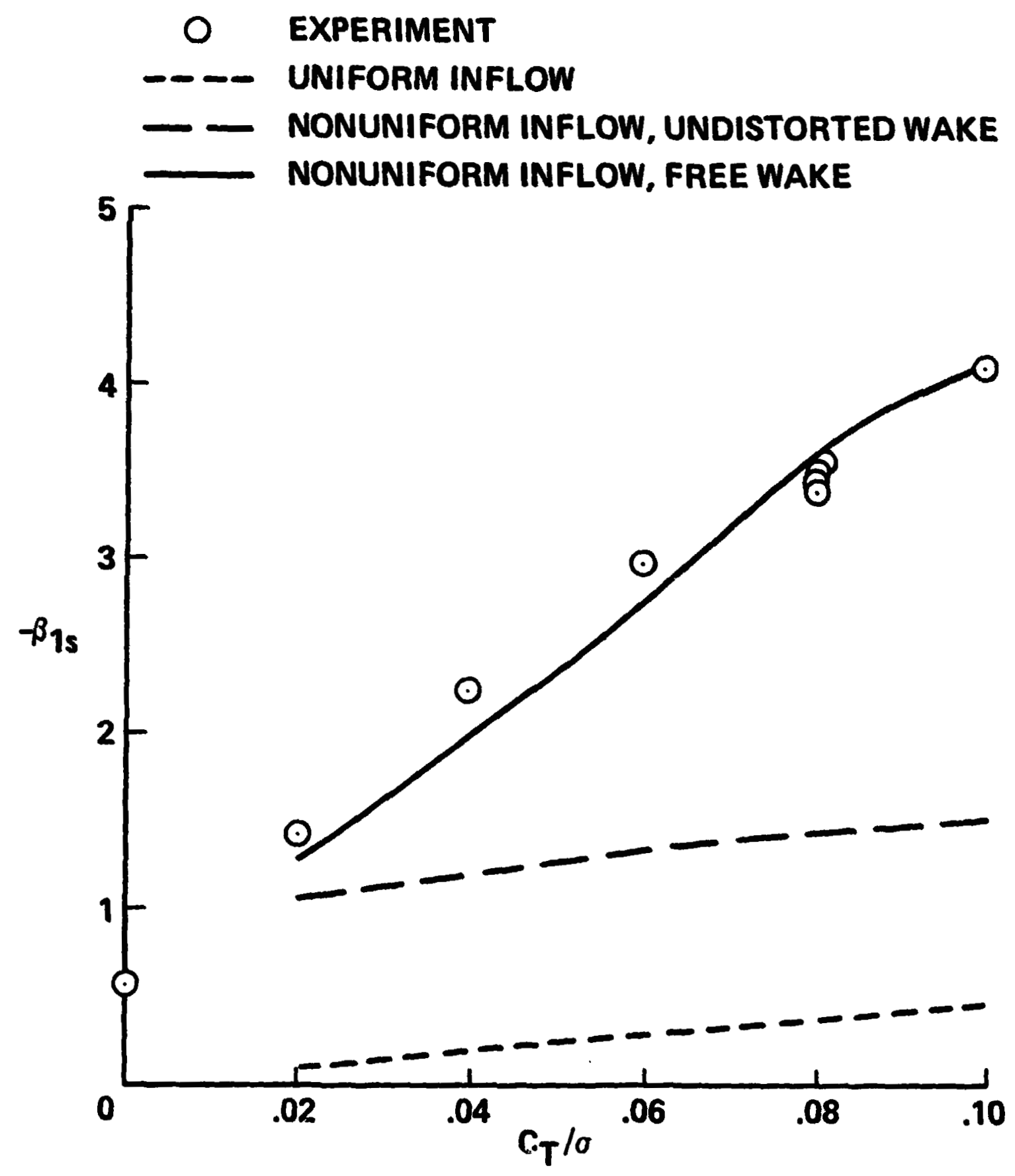

Figure 6. Comparison of measured and calculated model rotor lateral flapping angles as a function of thrust $\left(\mu=0.08\right.$ and $\left.\alpha_{s}=-1.35^{\circ}\right)$ 


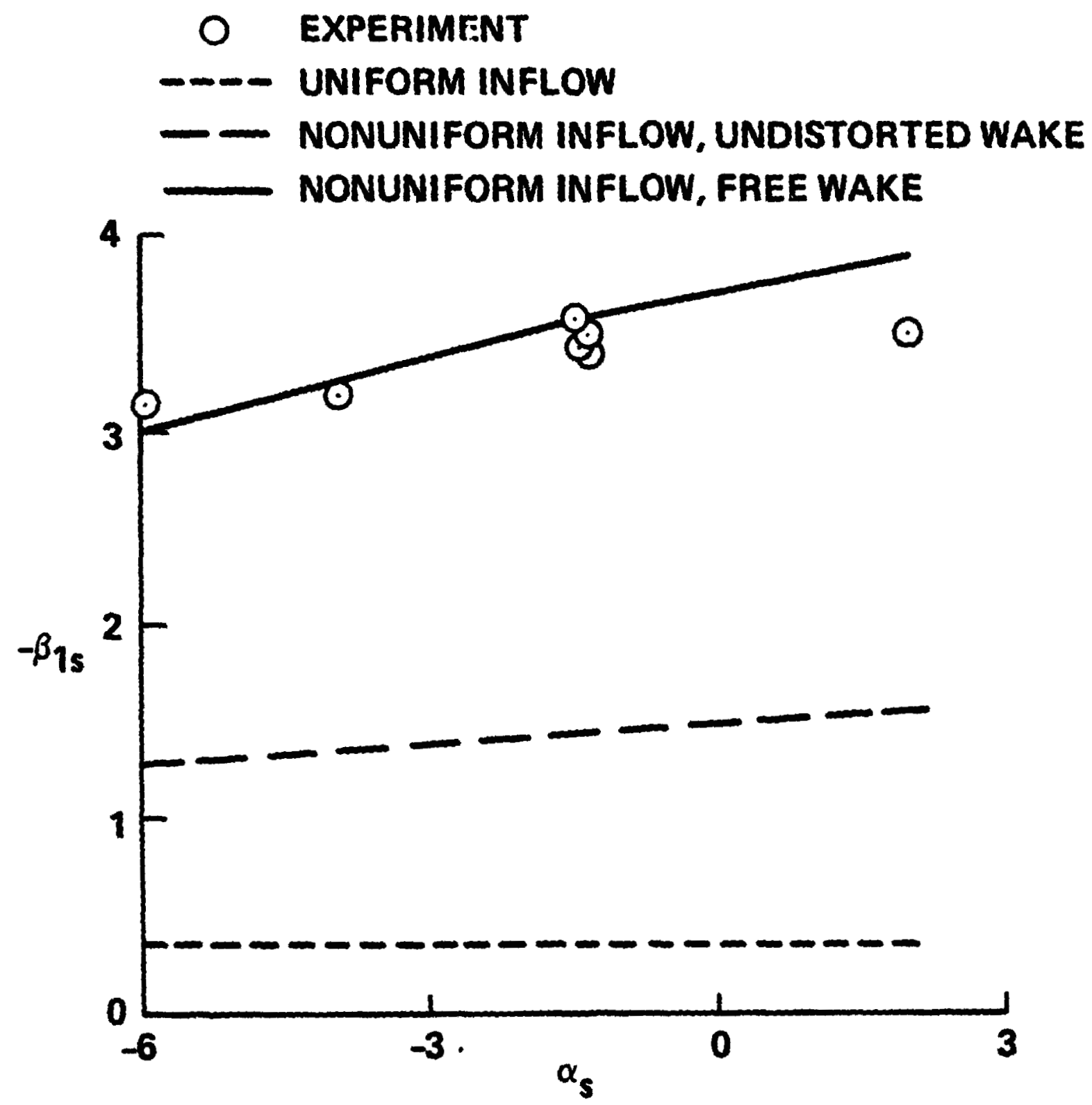

Figure ?. Comparison of measured and calculated model rotor lateral flappling angles as

a function of shaft angle $(\mu=0.08$

and $\left.\theta_{75}=11^{\circ}\right)$ 


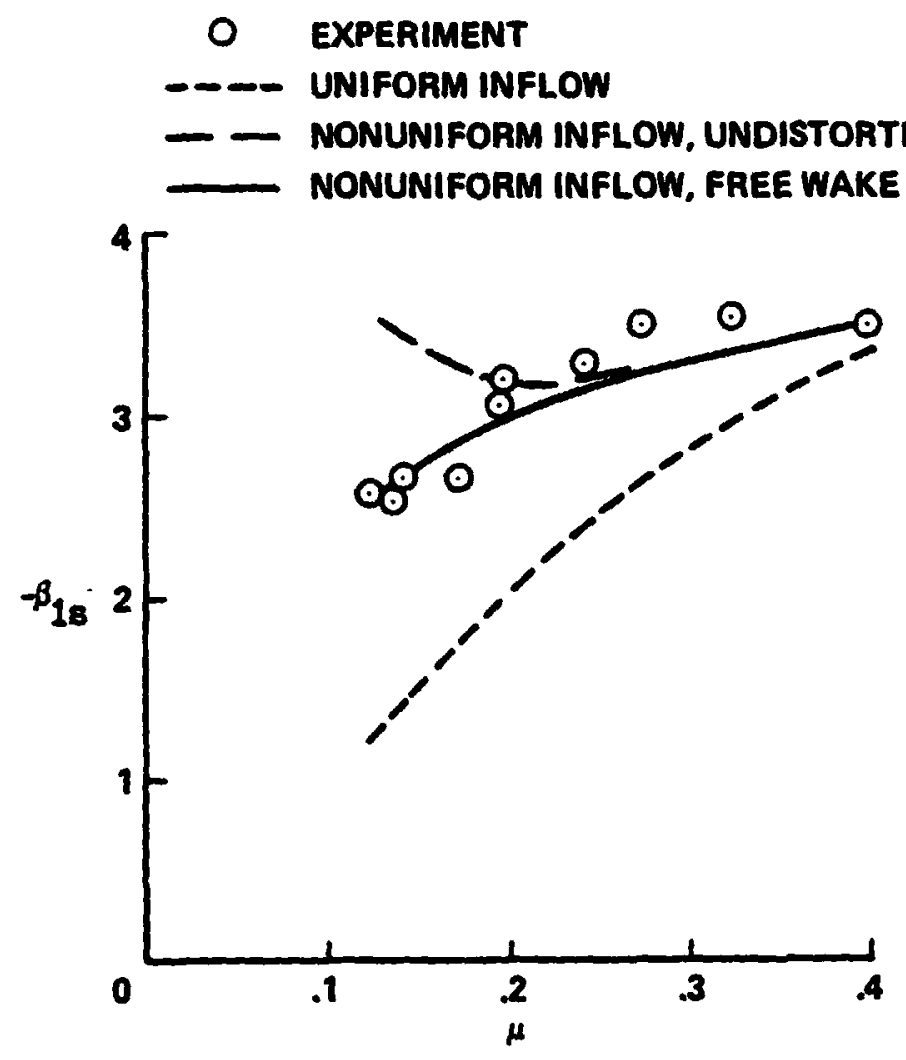

Figure 8. Comparison of me sured and calculated autogiro rotor lateral flapping angles as a function of advance ratio 